\title{
Heavy metal chelation tests: the misleading and hazardous promise
}

\author{
Perrine Hoet ${ }^{1}$ - Vincent Haufroid ${ }^{1,2}$. Dominique Lison ${ }^{1}$ (I)
}

Received: 22 June 2020 / Accepted: 9 July 2020 / Published online: 16 July 2020

c) Springer-Verlag GmbH Germany, part of Springer Nature 2020

Heavy metal screening is currently very popular, especially on the web, and has become a "must do" for an increasing number of patients. The relative availability of inductively coupled plasma mass spectrometry equipments capable of measuring multiple elements at once has boosted the diffusion of these practices. In most cases, the list of elements measured in these screens reflects the analytical capacity of the lab more than sound toxicological considerations. These "urine mobilization tests", "post-chelator challenges", "provocative chelations", "chelation challenges", or "challenge tests" (hereafter called "provocative chelation test" [PCT]) represent an appreciable business. The screen almost systematically reveals "heavy metal poisoning", and "detox cures" are generally recommended.

As academic toxicologists, we are increasingly consulted by patients anxious about their recent diagnosis of heavy metal poisoning based on the results of an overpriced PCT. Patients with vague and lingering complaints, without a clear diagnosis, who have often consulted several physicians are perfect targets for this business. In the short-term, these patients are often relieved to hear that someone has found a clue to their complex medical condition, and they enthusiastically undertake successive chelation cures.

An example, among others. Recently, the Belgian Federal Agency for Occupational Risks received a claim for recognizing and compensating neuropathic disorders caused by heavy metals as an occupational disease. The patient was on sick leave for more than 3 years, and though his general condition progressively worsened, he developed several manifestations, including a mild sensitive peripheral neuropathy. Blood and urine were collected in the absence of chelation and analyzed by a laboratory with successful

Dominique Lison

dominique.lison@uclouvain.be

1 Louvain Center for Toxicology and Applied Pharmacology, Institut de Recherche Expérimentale et Clinique, Université catholique de Louvain, Brussels, Belgium

2 Laboratory of Analytical Biochemistry, Cliniques Universitaires Saint-Luc, Brussels, Belgium results in external quality assessments. The results were within the reference values for the general population (lead, $23 \mu \mathrm{g} / \mathrm{L}$ blood, $0.66 \mu \mathrm{g} / \mathrm{L}$ urine; mercury, $<1.0 \mu \mathrm{g} / \mathrm{L}$ blood, $<0.50 \mu \mathrm{g} / \mathrm{L}$ urine; cadmium, $1.2 \mu \mathrm{g} / \mathrm{L}$ blood, $4.1 \mu \mathrm{g} / \mathrm{L}$ urine; thallium, $<0.5 \mu \mathrm{g} / \mathrm{L}$ blood, $0.14 \mu \mathrm{g} / \mathrm{L}$ urine; arsenic inorganic + methylated metabolites, $1.3 \mu \mathrm{g} / \mathrm{L}$ urine; creatinine, $0.91 \mathrm{~g} / \mathrm{L}$ urine). A second set of analyses performed 1 month later yielded similar results. Next, the patient underwent an additional analysis of 34 metals in urine after an intravenous administration of Zn-DTPA and DMPS, which was considered by the attending physician as being more relevant to objectify heavy metal intoxication. The results for several metals were interpreted as excessive by the laboratory, based on a comparison with "baseline urine norms": cadmium, $0.99 \mu \mathrm{g} / \mathrm{L}$; copper, $327 \mu \mathrm{g} / \mathrm{L}$; manganese, $8.9 \mu \mathrm{gL}$; lead, $16.5 \mu \mathrm{g} / \mathrm{L}$; mercrury, $4.1 \mu \mathrm{g} / \mathrm{L}$; nickel, $2.1 \mu \mathrm{g} / \mathrm{L}$ (creatinine $0.47 \mathrm{~g} / \mathrm{L}$ ). The patient was diagnosed with severe heavy metal poisoning on the basis of a tenfold "maximal value" for copper, eightfold for mercury, sevenfold for lead, fourfold for manganese, 2.5-fold for cadmium, and 1.5-fold for nickel. The Agency sought medico-technical expertise to document the case. Two comprehensive surveys of the past workplace exposure of the patient, including ambient air measurements, concluded on an absence of significant occupational exposure to heavy metals.

Both essential and nonessential metals may exert toxic effects if exposure exceeds certain levels. In most cases, careful clinical examination, a detailed occupational, domestic, and environmental history, and measurement of biological indicators in urine, blood, and/or hair will provide clues to the diagnosis. However, toxicological analyses should be performed by laboratories equipped for this purpose that can document proficiency in external quality controls. In some cases, a PCT may be advised when the interpretation of routine biological tests is not straightforward.

In the 1950s, physicians recognized the limitations of an isolated blood lead measurement to document impregnation when exposure was "not very severe", and introduced a lead mobilization test. These tests were particularly useful when a significant time period had elapsed since cessation 
of exposure (Teisinger and Srbova 1959). In the diagnosis of lead poisoning, difficulties may arise when lead stored in bone constitutes an endogenous source of exposure.

In 2020, essential information is still missing for relevant interpretation of a lead mobilization test, and no one-sizefits-all approach is applicable to other elements. The amplitude of the post-challenge urinary excretion will not only depend on the amount of metal absorbed, but also on the toxicokinetic properties of the metal (e.g., cumulative or not, storage organs), the efficacy of the agent to chelate the respective metals of interest, and the strategy used.

\section{There is no standardized protocol for PCTs}

The number of protocols for $\mathrm{Pb}$ chelation test in adults is almost as great as the number of users. Recommended modalities include intravenous injection or infusion of $1.2-25 \mathrm{mg} \mathrm{CaNa}{ }_{2}$ EDTA/kg body weight (bw) or $1-3 \mathrm{~g}$ $\mathrm{CaNa}_{2}$ EDTA diluted in saline or glucose solution, or oral administration of 5-10 mg DMSA $/ \mathrm{kg}$ bw or 1-2 g DMSA (Alessio et al. 1981; Bastenier 1963; Boudene et al. 1956; Emmerson and Thiele 1960; Hansen et al. 1981; Hoet et al. 2006; Lahaye et al. 1968; Lee et al. 1995; Salvini and Vidali 1955; Schwartz et al. 1994; Sokas et al. 1988; Teisinger and Srbova 1959).

Diverse strategies are also used for $\mathrm{Hg}$ mobilization: two intravenous injections of $1 \mathrm{~g} \mathrm{CaNa}_{2}$ EDTA (in $250 \mathrm{ml} 5 \%$ dextrose solution) at a 12-h interval, an IV of $2 \mathrm{mg} / \mathrm{kg}$ bw DMPS, an oral dose of $300 \mathrm{mg}$ DMPS or $30 \mathrm{mg}$ DMSA $/ \mathrm{kg}$ bw during a 2-h period, two oral doses of $10 \mathrm{mg}$ DMA/kg at an 8-h interval, $20 \mathrm{mg}$ DMSA/kg bw, or $2 \mathrm{~g}$ DMSA, among others. The recommended urine collection period varies between 3 and $24 \mathrm{~h}$, which highly influences the results, as the peak excretion rate depends on the kinetics of the chelating agent.(Aposhian et al. 1992; Archbold et al. 2004; Frumkin et al. 2001; Molin et al. 1991; Roels et al. 1991; Ruha et al. 2009; Sandborgh Englund et al. 1994; Vannes et al. 2000).

Several other protocols, without reference to a scientific publication, and sometimes combining two chelating agents, circulate on the web.

\section{There is no universal chelating agent}

Administering a single chelating agent to assess the excretion of more than 30 metals presumes that its efficacy is the same for all of these metals. However, efficacy varies according to the physicochemical properties of the metal and its speciation characteristics, the route of exposure, the intensity and extent of exposure, and the condition of the patient (Aaseth et al. 2016).
A thorough assessment of experimental and human data on chelating agents led to preliminary recommendations for their use as therapy. Desferal can be used for acute iron or aluminium poisoning, with deferipon and deferasirox being potential alternative chelators; DMPS for acute and chronic arsenic poisoning; DMSA for acute and chronic lead poisoning; DMPS for inorganic mercury compounds and mercury vapor, with DMSA likely being superior for organic mercury compounds; and triethylenetetramine for copper overload, with D-penicillamine as a second choice (Aaseth et al. 2016; Bjorklund et al. 2019).

\section{Comparing chelated levels to background reference values is misleading}

Trace elements, including metals, are ubiquitous in the environment, as they are released from the Earth's crust by weathering of rock minerals, by forest fires and volcanoes, and are bioconcentrated and dispersed by human activities, such as mining, industrial or agricultural processes, and use of consumer products. Detectable levels of lead, mercury, and other metals are present in biological fluids from individuals without specific (over)exposure. A prerequisite for identifying an individual with increased exposure is documentation of background concentrations of the chemical of interest in an appropriate reference population and the derivation of reliable reference values. The upper reference value is often set at the percentile 95 . This implies that $5 \%$ of results from this general healthy population fall outside this upper value, and are at risk of being labelled as 'abnormal'. Geological background levels and human activities are likely to differ between countries; therefore, the profile of exposure to trace elements in the general population may vary across populations.

A PCT boosts urinary trace elements excretion not only in "poisoned" subjects, but also in perfectly healthy individuals in whom the body burden is within reference levels. Comparing urinary excretion after chelation to reference ranges in the general population (in the absence of chelation) is nonsense. Reliable reference values for post-chelation urine are not available. Establishing such reference values is clearly an issue, because the level greatly depends on the protocol used. Therefore, the very first step would be to establish standardized protocols, which are likely to vary depending on the metal of interest in regards to the selected chelating agent, dose, and duration of urinary collection. 


\section{Interpreting reference values as critical thresholds indicating a health risk is misleading}

Reference levels have no intrinsic physiological or toxicological meaning. They are to be used for descriptive purposes, to identify individuals with an increased level of exposure compared with this background level. They do not represent a safe level. They are not "maximal values". They do not act as red flags indicating a health risk, a limit below or above which medical action is recommended. They should not be confused with a critical threshold indicating a health risk.

Comparing post-challenge to pre-challenge baseline concentrations is also an issue: what level of increase should be considered as significant in terms of toxicity?

A question is whether the increased excretion of the metal of interest in the post-challenge urine correlates with its body burden. Even more important is to know whether this correlation is clinically relevant. Chelation from storage organ(s) does not necessarily imply a therapeutic benefit. For example, lead is mainly stored in bones, whereas the brain is one of its main target organs. However, DMSA and DMPS mainly chelate $\mathrm{Pb}$ in the superficial bone layers and do not cross the blood brain barrier.

\section{Chelation is not without risk}

An ideal chelating agent should bind selectively to the metal of interest, resulting in the chelation and sufficient elimination of the metal in its toxic form without adverse health effects or affecting the concentrations of other essential elements (Aaseth et al. 2016). No chelating agent meets this criterion. For example, the side effects of $\mathrm{CaNa}_{2}$ EDTA, a commonly used chelating agent, include local reactions at the injection site, hypersensitivity reactions, fever, calcium dysregulation, renal dysfunction, and loss of essential minerals such as iron, copper, and zinc. Even safer alternatives, such as DMSA or DMPS, may increase the elimination of certain essential elements, and side effects include abdominal distress, transient rash, elevated circulating liver transaminases, and neutropenia. This may not be significant when used for a single provocation test, but the problem may become important for patients enrolled in successive chelation cures to rid their body of a "toxic burden". The patient who put in a claim for recognition of an occupational disease started a chelation cure every 4 weeks soon after his diagnosis of "severe heavy metal intoxication". In view of his PCT results, he was at high risk of inducing copper deficiency, possibly resulting in an aggravation of his neurological disorder.

Chelating agents are great drugs when used wisely, and excellent reviews are available on the topic. No universal chelator, that is safe and efficacious against all metals, is available, and these drugs should be handled by expert physicians aware of their properties and the toxicology of metals (Aaseth et al. 2016).

Several experts have reviewed relevant data on PCTs and underlined the lack of scientific background, calling for caution when using them (Greiner and Drexler 2016; Jones et al. 2019; Ruha 2013). In 2009, the American College of Medical Toxicology (ACMT) issued a position statement disapproving of the use of PCTs in clinical practice and the use of the results of these tests as an indication for further chelation treatment. (ACMT 2010). In 2012, experts from the ACMT, the U.S. Centers for Disease Control (CDC), the Agency for Toxic Substances and Disease Registry, and others reviewed the use and misuse of chelation therapy in the United States for the treatment of metal poisoning. They concluded that incorrect diagnosis of metal poisoning was common and criticized the widespread misdiagnosis of poisoning by lead, arsenic, mercury, and other metals, calling for strong efforts to reduce the inappropriate use of metal chelation therapy (McKay 2013). In 2017, after reviewing new data, the ACMT confirmed their previous conclusion that PCT is not scientifically validated, does not demonstrate benefit, and could be harmful (ACMT 2017). Yet, the business is booming.

Metals overexposure may be associated to a variety of adverse effects and relevant metal testing is important. We want to alert the medical community about procedures that are currently far from being validated.

Author contributions $\mathrm{PH}, \mathrm{VH}$ and DL conceptualized the Viewpoint and contributed to its development. PH did the literature search and wrote the first draft. All authors gave final approval of the version to be submitted.

Funding No funding.

\section{Compliance with ethical standards}

Conflict of interest We declare no competing interests.

\section{References}

Aaseth J, Crisponi G, Andersen O (2016) Chelation therapy in the treatment of metal intoxication. Elsevier Inc, Academic Pess, $\mathrm{p}$ $388 \mathrm{p}$

ACMT-American College of Medical Toxicology (2010) ACMT position statement on post-chelator challenge urinary metal 
testing. J Med Toxicol 6:74-75. https://doi.org/10.1007/s1318 1-010-0039-0

ACMT-American College of Medical Toxicology (2017) ACMT recommends against use of post-chelator challenge urinary metal testing. J Med Toxicol 13:352-354. https://doi.org/10.1007/s1318 1-017-0624-6

Alessio L, Castoldi MR, Odone P, Franchini I (1981) Behaviour of indicators of exposure and effect after cessation of occupational exposure to lead. Br J Ind Med 38:26-267. https://doi. org/10.1136/oem.38.3.262

Aposhian HV, Bruce DC, Alter W, Dart RC, Hurlbut KM (1992) Aposhian MM. Urinary mercury after administration of 2,3-dimercaptopropane-1-sulfonic acid: correlation with dental amalgam score. FASEB J 6:2472-2476. https://doi.org/10.1096/ fasebj.6.7.1563599

Archbold GP, McGuckin RM, Campbell NA (2004) Dimercaptosuccinic acid loading test for assessing mercury burden in healthy individuals. Ann Clin Biochem 41:233-236. https://doi. org/10.1258/000456304323019622

Bastenier H (1963) Considerations on the diagnosis and treatment of lead poisoning of occupational origin. Acta Clin Belg 18:144-151

Bjorklund G, Crisponi G, Nurchi VM, Cappai R, Buha Djordjevic A, Aaseth J (2019) A review on coordination properties of thiolcontaining chelating agents towards mercury, cadmium, and lead. Molecules 24:3247. https://doi.org/10.3390/molecules24183247

Boudene C, Chain F, Clavel B et al (1956) Efficiency of ethylenediaminetetraacetic acid calcium salt in occupational lead poisoning. Arch Mal Prof 17:423-429

Emmerson BT, Thiele BR (1960) Calcium versenate in the diagnosis of chronic lead nephropathy. Med J Aust 47:243-248

Frumkin H, Manning CC, Williams PL, Sanders A, Taylor BB, Pierce M, Elon L, Hertzberg VS (2001) Diagnostic chelation challenge with DMSA: a biomarker of long-term mercury exposure? Environ Health Persp 109:167-171. https://doi.org/10.1289/ehp.01109 167

Greiner A, Drexler H (2016) Unnecessary investigations in environmental medicine. Dtsch Arztebl Int 113:773-780. https://doi. org/10.3238/arztebl.2016.0773

Hansen JP, Dossing M, Paulev PE (1981) Chelatable lead body burden (by calcium-disodium EDTA) and blood lead concentration in man. J Occup Med 23:39-43. https://doi.org/10.1097/00043764198101000-00017

Hoet P, Buchet JP, Decerf L, Lavalleye B, Haufroid V, Lison D (2006) Clinical evaluation of a lead mobilization test using the chelating agent dimercaptosuccinic acid. Clin Chem 52:88-96. https://doi. org/10.1373/clinchem.2005.051128

Jones SL, Campbell B, Hart T (2019) Laboratory tests commonly used in complementary and alternative medicine: a review of the evidence. Ann Clin Biochem 56:310-325. https://doi. org/10.1177/0004563218824622

Lahaye D, Roosels D, Verwilghen R (1968) Diagnostic sodium calciumedetate mobilization test in ambulant patients. Br J Ind Med 25:148-149. https://doi.org/10.1136/oem.25.2.148
Lee BK, Schwartz BS, Stewart W, Ahn KD (1995) Provocative chelation with DMSA and EDTA: evidence for differential access to lead storage sites. Occup Environ Med 52:13-19. https://doi. org/10.1136/oem.52.1.13

McKay CA Jr (2013) Editorial: Use and misuse of metal chelation therapy. J Med Toxicol 9:301-302. https://doi.org/10.1007/s1318 1-013-0349-0

Molin M, Schutz A, Skerfving S, Sallsten G (1991) Mobilized mercury in subjects with varying exposure to elemental mercury vapour. Int Arch Occup Environ Health 63:187-192. https://doi. org/10.1007/BF00381567

Roels HA, Boeckx M, Ceulemans E, Lauwerys RR (1991) Urinary excretion of mercury after occupational exposure to mercury vapour and influence of the chelating agent meso-2,3-dimercaptosuccinic acid (DMSA). Br J Ind Med 48:247-253. https://doi. org/10.1136/oem.48.4.247

Ruha A-M (2013) Recommendations for provoked challenge urine testing. J Med Toxicol 9:318-325. https://doi.org/10.1007/s1318 1-013-0350-7

Ruha AM, Curry SC, Gerkin RD, Caldwell KL, Osterloh JD, Wax PM (2009) Urine mercury excretion following meso-dimercaptosuccinic acid challenge in fish eaters. Arch Pathol Lab Med 133:87-92. https://doi.org/10.1043/1543-2165-133.1.87

Salvini M, Vidali U (1955) Urinary lead elimination after treatment with calcium disodium ethylenediamine tetraacetate. Folia Med (Napoli) 38:579-592

Sandborgh Englund G, Dahlqvist R, Lindelöf B, Söderman E, Jonzon B, Vesterberg O, Larsson KS (1994) DMSA administration to patients with alleged mercury poisoning from dental amalgams: a placebo-controlled study. J Dent Res 73:620-628. https://doi org/10.1177/00220345940730030701

Schwartz BS, McGrail MP, Stewart W, Pluth T (1994) Comparison of measures of lead exposure, dose, and chelatable lead burden after provocative chelation in organolead workers. Occup Environ Med 51:669-673. https://doi.org/10.1136/oem.51.10.669

Sokas RK, Atleson J, Keogh JP (1988) Shortened forms of provocative lead chelation. J Occup Med 30:420-424. https://doi. org/10.1097/00043764-198805000-00008

Teisinger J, Srbova J (1959) The value of mobilization of lead by ethylenediamine-tetra-acetate in the diagnosis of lead poisoning. $\mathrm{Br}$ J Ind Med 16:148-152

Vamnes JS, Eide R, Isrenn R, Hol PJ, Gjerdet NR (2000) Diagnostic value of a chelating agent in patients with symptoms allegedly caused by amalgam fillings. J Dent Res 79:868-874. https://doi. org/10.1177/00220345000790031401

Publisher's Note Springer Nature remains neutral with regard to jurisdictional claims in published maps and institutional affiliations. 